\title{
Case report - Prolonged SARS-CoV-2 positive PCR after resolution of symptoms
}

\author{
Federica Gigli ${ }^{1}$, Daniele Laszlo ${ }^{1}$, Daniele Avenoso*2 \\ ${ }^{1}$ Division of Haemato-Oncology, European Institute of Oncology IRCCS, Viale Ripamonti, Milano, Italy \\ ${ }^{2}$ Department of Haematological Medicine, King's College Hospital, Denmark Hill, London, United Kingdom
}

Received: May 28, 2020

Accepted: June 14, 2020

Online Published: June 19, 2020

DOI: $10.5430 / \mathrm{dcc} . \mathrm{v} 7 \mathrm{n} 1 \mathrm{p} 1$

URL: https://doi.org/10.5430/dcc.v7n1p1

\begin{abstract}
The recent SARS-CoV-2 pandemic is a new challenge for clinicians worldwide. Although the clinical aspects are well described by different groups, there are still some areas of uncertainty about the interpretation of diagnostic methods. Herein, we describe the clinical case of a 45-year-old lady that contracted SARS-CoV-2 infection with a prolonged PCR positive nasopharyngeal swab but lack of COVID-19 defining events.
\end{abstract}

Key Words: SARS-CoV-2, COVID-19, Nasopharyngeal PCR, COVID-19 antibodies

\section{BACKGROUND}

In December 2019, the detection of novel Severe Acute Respiratory Syndrome Coronavirus 2 (SARS-CoV-2), responsible for Coronavirus Disease 2019 (COVID-19), ${ }^{[1]}$ has been a new challenge for the medical community.

Difficulty in making the diagnosis of COVID-19, both from a clinical and laboratory point of view, is one of the challenges that worldwide clinicians face. ${ }^{[2]}$

Further, insufficient data about antibody response and viral clearance from the respiratory tract in symptomatically recovered patients leave unsnawered questions.

\section{Objective}

Herein, we report the case of a patient that successfully recovered from SARS-CoV-2 infection with persistence of positive PCR on samples from nasopharyngeal swabs 6 weeks after the onset of the disease. The aim of the current report is to give more information about viral clearance in patient without COVID-19.

\section{CASE REPORT}

A 45-year-old Italian lady with unremarkable past medical history developed flu like symptoms on $13^{\text {th }}$ March 2020, characterized by low grade fever $\left(37.4^{\circ} \mathrm{C}\right)$ and bone pains. Oxygen saturations on room air were within normal limits (SpO2 98\%-99\%) although were associated with moderate tachycardia (heart rate $120 \mathrm{bpm}$ ). Five days after the onset of these symptoms she developed anosmia and the following day validated PCR on nasopharyngeal swab ${ }^{[3]}$ confirmed the clinical suspicion of SARS-CoV2 infection.

Due the absence of COVID-19 defining events ${ }^{[4]}$ the patient self-isolated at home and had clinical monitoring; she never required oxygen supplementation. Nine days after the onset of fever there was resolution of anosmia.

On $2^{\text {nd }}$ April (day 15 post symptom onset), she was completely asymptomatic and had a second nasopharyngeal swab

\footnotetext{
*Correspondence: Daniele Avenoso; Email: d.avenoso@nhs.net; Address: Department of Haematological Medicine, King’s College Hospital, Denmark Hill, London, United Kingdom. 
that was weakly positive. Based on that result a new swab was done one week later and it was still weakly positive.

Thirty-one days after the onset of the disease, the swab was negative for the first time; considering the high rate of false negative results, another test was performed few days after and showed again the presence of the virus.

On the same day, a rapid test for serology was performed and showed positivity for IgG and absence of IgM in keeping with previous infection. Another serology test was performed the following day that confirmed the presence of IgG but also of IgM.

A new PCR evaluation was performed and was still weakly positive and a third serology evaluation was suggestive for previous infection due the presence of only IgG.

The positivity of the swab persisted after 1 month and 5 days despite the absence of symptoms. Fifty-three days from the SARS-CoV-2 infection, the qualitative PCR from nasopharyngeal samples was negative on two consecutive occasions.

\section{Discussion \& Conclusions}

Currently, the majority of respiratory symptoms (including those responsible for rapid clinical deterioration) are attributed to the immune response against the viral infection Indeed, the hypothesis of severe inflammation resulting in a more severe disease phenotype have resulted in trial proposals of agents blocking these pathways for treatment or prevention of severe consequences of SARS-CoV-2. ${ }^{[5]}$

It is intriguing to suggest that patients with mild symptoms or without any COVID-19 events may not develop an exaggerated immune response against SARS-CoV-2. Thus, the prolonged positivity of nasopharyngeal swab and the pres- ence of anti-SARS-CoV-2 IgM, may reflect the persistence of the virus suggesting that these patients may have a longer recovery time; the consequence of it could be the requirement of prolonged isolation to prevent the spreading of the infection.

Therefore, it is reasonable to suggest that it is necessary to consider qualitative serological antibody status with the quantitative evaluation of the antibodies, aiming to identify a threshold that allows to clarify patients that cleared the viral infection and developed immunity against it.

On the other hand, other groups suggest that some patients may still be prolonged PCR positive where expression of viral RNA does not necessarily indicate presence of viable virus. ${ }^{[6]}$ These pitfalls in interpretation of the clinical significance of weakly positive PCR swabs are a challenge, especially amongst health workers that have contracted the disease and may require unnecessary prolonged isolation.

It is mandatory to collect data from SARS-CoV-2 patients without COVID-19, aiming to understand the kinetics of viral clearance from the nasopharyngeal mucosa alongside the determination of an antibody threshold for immunity.

\section{ACKNOWLEDGEMENTS}

We thank our colleagues worldwide for the extraordinary job performed in this global crisis.

\section{Authors' CONTRIBUtions}

FG, DL and DA were involved in the care of the patient and wrote the manuscript.

\section{CONFLICTS OF INTEREST Disclosure}

The authors declare they have no conflicts of interest.

\section{REFERENCES}

[1] Zhu N, Zhang D, Wang W, et al. A Novel Coronavirus from Patients with Pneumonia in China, 2019. N Engl J Med. 2020; 382(8): 727-33. PMid:31978945. https ://doi.org/10.1056/NEJMoa2001017

[2] Sethuraman N, Jeremiah SS, Ryo A. Interpreting Diagnostic Tests for SARS-CoV-2. JAMA. 2020. PMid:32374370. https://doi or $\mathrm{g} / 10.1001 /$ jama.2020.8259

[3] Corman VM, Landt O, Kaiser M, et al. Detection of 2019 novel coronavirus (2019-nCoV) by real-time RT-PCR. Eurosurveillance. 2020; 25(3): 2000045. https://doi .org/10 . 2807/1560-7917. ES.2020.25.21.2001035
[4] Wu Z, McGoogan JM. Characteristics of and Important Lessons From the Coronavirus Disease 2019 (COVID-19) Outbreak in China. JAMA. 2020; 323(13): 1239. PMid:32091533. https ://doi .org/ 10.1001/jama.2020.2648

[5] Zirui Tay M, Meng Poh C, Ramp L, et al. The trinity of COVID-19: immunity, inflammation and intervention. Nat Rev Immunol. 2020; 20(6): 363-374. PMid:32346093. https ://doi.org/10.1038/s4 1577-020-0311-8

[6] Wölfel R, Corman VM, Guggemos W, et al. Virologicalassessment of hospitalized patients with COVID-2019. Nature. 2020; 581(7809): 465-469. PMid:32235945. https ://doi.org/10.1038/s41586 $-020-2196-x$ 